\title{
PENINGKATAN MUTU KOMUNIKASI PEMUDA YANG BERETIKA DAN CERDAS DENGAN SEMANGAT AJARAN VEDA
}

\author{
Oleh \\ Ni Gusti Ayu Kartika \\ Institut Hindu Dharma Negeri Denpasar \\ nigustiayukartika@gmail.com
}

Diterima 28 November 2017, direvisi 15 Januari 2018, diterbitkan 28 Pebruari 2018

\begin{abstract}
In an attempt to build ethnic Hindu youth and ethnic youths who are ethical and intelligent according to Hindu teachings, Hindu youth must understand and apply the formula of Hindu teachings through understanding and application of Hindu philosophical teaching or tattwa or darsana, understanding and application of Hindu moral teachings, as well as appreciation and practice of the Hindu religious ceremony on a regular basis (nitya karma) as well as within the appointed time (naimitika karma). The three core formulations of the teachings of Hinduism according to the source in the Vedas, should be understood in full and berintegratif anatara one doctrine with other teachings that support each other and unite in implementation.

The importance of Hindu youth to understand the meaning of the teachings of Hinduism through tattwa, also very useful also ethical or ethical Hindu material to be the basis of ground, apply, and berkarma, so that his movement leads to good deeds (susila or subhakarma). This is not the ideals of the Hindu youth, because the ideals of the Hindu youth are for the realization of wise young Hindu cadres (gunamantha), wisdom (prajna), intelligent wisesa), acting well (sadhu), doing right (sukarma or subhakarma), diligent work (karmani) is not lazy to work (akarmani), apply full value (mulya karma), as well as being a good and right young (suputra-suputri).
\end{abstract}

\section{Keywords: Quality Improvement, Youth Communication, Ethics And Smart, Veda}




\section{PENDAHULUAN}

Pemuda merupakan modal bangsa Indonesia yang wajib diberikan perhatian secara baik dan benar dari lini manapun. Termasuk juga kali ini adalah adanya upaya pasraman yowana atau pelatihan pemuda yang dilakukan oleh Peradah Provinsi Jawa Timur, sebagai wujud kepedulian dan tanggung jawab yang tinggi untuk masa depan yang lebih baik. Hal ini patut diacungi jempol, oleh karena upaya seperti ini merupakan upaya positif, upaya konstruktif, serta upaya untuk mendinamiskan gerak dan perilaku para pemuda Hindu.

Disadari bahwa pada masa silam bahwa pemuda pada umumnya termasuk para pemuda Hindu telah memberikan andil yang sangat besar terhadap upaya perjuangan dan pergerakan menuju terwujudnya negara Indonesia yang merdeka serta dapat mewujudkan ketentraman serta kesejahteraan umat manusia di tanah air tercinta Indonesia. Begitu seterusnya sampai pada masa kini bahwa peran pemuda, termasuk pemuda Hindu tidak pernah berhenti untuk berbuat atau berkarma dalam kiprahnya untuk mengisi, menata, mengembangkan pembangunan bangsa Indonesia ini, sekaligus juga mengisi pembangunan kehidupan beragama secara umum maupun kehidupan beragama Hindu secara khusus. Pembangunan kehidupan beragama Hindu wajib digenjot terus dalam pencapaiannya, oleh karena dalam gerak langkahnya jangan sampai tertinggal dari sesama umat beragama yang lainnya. Pemuda Hindu diwajibkan turut berkompetisi secara positif dan adaptif guna turut secara bergandengan tangan antara yang satu dengan yang lainnya dalam mengupayakan umat Hindu yang gemah ripah loh jinawi tata tentrem kerta raharja.

Diantaranya kata membangun artinya bengkit berdiri, naik, mulai sadar (tim penyusun, 1994:89), peribadi artinya manusia sebagai perseorangan, keseluruhan sifat-sifat yang merupakan watak orang (ibid, 788), pemuda artinya orang muda laki-laki, remaja, teruna dan pemudi artinya orang muda perempuan, remaja putri, gadis (ibid, 745), beretika artinya memiliki ilmu tentang apa-apa yang baik dan apa yang buruk dan tentang hak dan kewajiban moral (akhlak) (ibid, 371), cerdas artinya sempurna perkembangan akal budinya (untuk berpikir, mengerti, dsb), tajampikiran, sempurna pertumbuhan tuhannya (sehat, kuat) (ibid, 186), semangat artinya seluruh kehidupan batin manusia, kekuatan, perasaan hati (ibid, 903), ajaran adalah segala sesuatu yang diajarkan, nasihat, petuah, petunjuk (ibid, 15), dan kata Veda atau Weda adalah kitab suci agama Hindu yang tertua (ibid, 1128). Jadi dapat diartikan sebagai upaya untuk membangkitkan insan pemuda dan pemudi Hindu dalamberlaku secara baik ataumulia guna menuju kesempurnaan dalam pertumbuhan pikiran dan fisik secara baik dan bersemangat berlandaskan pada nilai ajaran atau petunjuk suci yang tersurat pustaka suci Veda.

\section{PEMBAHASAN}

\subsection{Veda Sebagai Sumber Ajaran Agama Hindu}

Pustaka suci Vedaadalah sebagai sumber ajaran agama Hindu. Selain itu, bagi umat Hindu di Bali pada khususnya dan indonesia pada umumnya, juga menggunakan beberapa sumber lokal sebagai sumber ajaran agama Hindu. Sumber-sumber yang dimaksudkan, misalnya : bhuwana kosa, wrhaspati tattwa, siwa tattwa purana, bhuwana sang ksepa, tattwa jnana, ganapati tattwa, sang hyang maha jnana, yama purana tattwa, yama purwana tattwa, yama tattwa, dan sebagainya.

Dalam pustaka suci Manawadharmasastra yaitu pada dwitya adhyaya atau bab kedua, sloka keenam ada dinyatakan mengenai sumber ajaran Hindu Dharma (Agama Hindu). Bunyi slokanya seperti berikut ini. 
Idanin dharma pramananyaha; wedio "kilo dharma mulam, smrtisile ca tad widam, acarascaiwa sadhunam atmanastustirewa ca.

Artinya:

seluruh pustaka suci Weda adalah sumber pertamadari pada dharma kemudian adat istiadat, dan lalu ttingkah laku yang terpuji dari orang-orang budiman yang mendalami ajaran pustaka suci Weda, juga tata cara perikehidupan orang-orang suci dan akhirnya kepuasan dari pribadi (G. Pudja dan Tjok Rai Sudharta, 1976 atau 1977:62).

Kutipan sloka di atas menegaskan bahwa sumber ajaran agama Hindu mencakup : 1) Weda, 2) smerti 3) sila atau perilaku yang baik atau terpuji, 4) acara atau adat-istiadat, 5) atmanastusti atau kepuasan diri pribadi atau pikiran baik perorangan. Kemudian lebih lannjut dalam sloka sepuluh ditegaskan pula tentang sumber ajaran agama Hindu sepertiberikut ini.

\section{Srutistu wedo wijneyo,}

dharmasastram tu wai smertih, te sar-watheswamimamsye tabhyam dharmohi nirbabhau.

Artinya:

dharma sastra, kedua macam pustaka suci ini tidak boleh diragu-ragukan kebenarannya mengenai apapun juga karena dari keduanya itu hukum (ibid, 63).

Menyimak kutipan sloka di atas, bahwa sumber ajaran agama Hindu adalah Weda, yang meliputi: 1) sruti sebagai sumber utama Weda, dan 2) smrti adalah dharmasastra sebagai sumber kedua Weda. Dapat ditegaskan, bahwa agama Hindu memiliki sumber ajaran berupa pustaka suci Weda. Namun demikian tidak berarti bahwa sumber yang lainnya tidak penting. Sumber dalam Weda maupun sumber- sumber lokal sama-sama pentingnya, sebagaimana beberapa sumber penting yang telah disebutkan di atas tadi.

Umat Hindu memiliki empat tujuan yang disebut dengan Catur Purusa Artha. Keempat tujuan itu antara lain: dharma, artha, kama, dan moksha. Beberapa orang India menyatakan tentang empat tujuan kehidupan manusia (dharma), yaitu kekayaan (artha), kenikmatan (kama), kewajiban (moksa), dan pembebasan (moksa) (Maswinara, 1999:36). Yang paling utama tujuan hidup adalah untuk menegakkan kebenaran (dharma). Dalam berpikir, berkata, dan berbuat seharusnya atas dasar kebenaran. Jika dharma ditegakkan, maka segala material atau jenis kekayaan (artha), akan diperoleh secara benar pula. Memiliki artha atas dasar kebenaran adalah kekayaan yang sejati dan termulia. Artinya artayang demikian akan bisa sebagai sarana menuju cita-cita hidup (kama) yang mulia pula. Ketiga tujuan mulia itu adalah sebagai tujuan hidup secara real (sakala) di dunia ini. Jika semua tercapai maka tinggallah mewujudkan tujuan yang terakhir atau (niskala), yaitu kelepasan hidup yang tanpa ikatan duniawi ( $m o k s a$ ). Jadi demikianlah sebagai tujuan hidup umat Hindu tujuan utama dalam agama Hindu, yaitu tercapai hidup yang bahagia (bhagya), sejahtera (hita), serta tenteram (santosam), yang juga diucapkan dengan istilah "mokshartam jagad hita ya ca iti dharmah".

Selain memiliki tujuan hidup yang sangat utama, bahwa umat Hindu termasuk para pemudanya agar meyakini ajaran kepercayaan agama Hindu (sraddha). Ada lima kepercayaan yang wajib diyakini yang dinamai Panca Sraddha. Ajaran agama Hindu mengajarkan umat Hindu untuk meyakini dan percaya dengan keesaan adanya Tuhan Yang Maha Esa. Tidak saja kepada Tuhan tetapi juga tetap percaya terhadap empat aspek yang lainnya. Ajaran tentang keyakinan dalam Hindu disebut sradha. Ada lima keyakinan dasar dalam agama Hindu (Panca Sradha). Bagian-bagian kelima 
sradha tersebut meliputi : percaya dengan Tuhan (Widhi Sradha), percaya dengan adanya percikanterkecil dari Tuhan (Atma Sradha), percaya dengan segala perbuatan pasti mebuahkan hasil dan diterima oleh yang melakukannya (Karma Phala Sradha), percaya dengan kehidupan manusiadi dunia ini selalu mengalami penjelmaan kembali atau reincarnation (Samsara atau Punarbhawa Sradha), dan juga percaya dengan kelepasan manusia dengan ikatan duniawi (Moksha).

\subsection{Pemuda Hindu Yang Beretika dan Cerdas Menurut Weda}

Tata Susila Hindu adalah tata aturan dalam berperilaku yang baik dan benar menurut Hindu. Tata Susila atau etika merupakan hal yang utama bagi kehidupan manusia dalam hidup bersama, antara yang satu dengan yang lainnya. Perlunya tata susila itu adalah untuk mengatur cara hidup manusia dalam kehidupan sehari-hari, baik dalam kondisi individual maupun kebersamaan. Jika seseorang berlaku sesuai tata susila, maka seseorang itu menjadi selamat dalam berbuat, serta ada dalam bingkai perbuatan yang baik dan benar. Begitu pula dalam kondisi kebersamaan, bahwa siapapun diantara sesama manusiaitu, wajib untuk menaati segala perilaku yang berlandaskan pada tata susila. Harapannya adalah agar tercapai kebaikan dalam hidup bersama pula.

Ajaran mengenai tata susila Hindu, mencakup : tiga perilaku yang suci (tri kaya parisudha), yakni : berbuat yang baik dan benar (wacika parisudha), berkata yang baik dan benar (wacika parisudha) dan berpikir yang baik dan benar (manacika parisudha). Dalam hidup diperlukan pengendalian diri (mulat sarira). Juga pengekangan diri (tapa). Dalam hidup diperlukan pengendalian diri secara internal (yama brata) mencakup : ahimsa atau tidak menyakiti, brahmacari atau menuntut ilmu, satya atau benar atau setia, awyawaharika atau tanpa ikatankeduniawian, dan asteya atautidak mencuri, serta pengendalian diri secara external (niyama brata) mencakup : akroda atau tidakmarah, gurususrusa atau hormat pada ajaran guru, sauca atau kesucian lahir batin, aharalagawa atau makan sederhana, dan apramada atau tidak lalai pada kewajiban atau tidak ingkar. Selain itu bahwa hidup perlu menjauhkan segala musuh dalam diri berupa enam musuh ( $s a d$ ripu), mencakup kama atau keinginan, lobha atau rakus, krodha atau marah, mada atau mabuk, moha atau bingung, dan matsarya atau iri hati. Tidak saja itu, juga segala kegelapan diri perlu dientaskan, yang sangat berbahaya yang terdiri atas tujuh kegelapan (sapta timira) mencakup : surupa ataugelap karena keremajaan, sura ataugelap karena ketampanan, dhana atau gelap karena kekayaan, gunal atau gelap karena keremajaan, sura atau gelap karena minuman keras, dan kasuran atau gelap karena kemenangan, sura atau gelap karena minuman keras, dan kasuran atau gelap karena kemenangan. Kemudian dalam berperilaku perlu menghindari tiga hal yang kotor (tri mala), yakti : moral atau kebingungan, mada ataucongkak dan sombong, dan kasmala atau perbuatan kotor. Enam perilaku bengis atau kejam (sad atatayi) perlu dihindari, meliputi : agnida atau membakar; wisada atau meracun, atharwa atau melakukan ilmu hitam, sastragma atau mengamuk, dratikrama atau memperkosa, dan raja pisuna atau memfitnah.

Dalam konteks kehidupan beragama Hindu melalui praktek upacara agama Hindu. Oleh karena praktek beragama Hindu melalui praktek upacara agama Hindu. Oleh karena praktek beragama Hindu itu membuat pemuda Hindu dapat eksis dalam kancah keberagamaan Hindu, yang pada akhirnya sebagai sebagai pembangkit inspirasi menuju pada level kecerdasan yang lainnya, baik dalam ilmu terapan atau praktek atau skill knowledge yang lainnya (apllied science) atau vijnana. Maka dari itu bahwa spirit berupacara agama 
Hindu wajib sebagai modal utama untuk menuju pada jenjang kecerdasan yang lebih komplek. Melalui upacara agama Hindu bahwa pemuda Hindu dituntut untuk selalu berbakti kepada Tuhan, berbakti kepada sesama, berbakti kepada lingkungan, termasuk juga disini dapat mencintai berbagai ilmu pengetahuan (sarva jnana) yang harus ditimpa sebagai bekal dalam hidupnya. Berkenaan dengan inti ajaran upacara agama Hindu sebagai inspirator intelektual pemuda Hindu dapat disimak paparan berikut ini.

Dalam pustaka suci Manawadharmasastra terutama pada tritiyo'dhyayah (bab ketiga), sloka 68, 69,70 dan 71 ada ditegaskan tentang upacara persembahan dalam agama Hindu. Secara praktis bahwa umat Hindu telah tidak asing dalam melaksanakan lima persembahyangan (Panca Yajna). Adapun lima persembahan tersebut, seperti kutipan sloka berikut ini.

Panca suna grhasthasya culli pesanyu paskarah,

kandani codakumbhasca badhyate yastu wahayan.

Artinya :

Seorang kepada rumahkeluarga mempunyai lima macam tempat penyembelihan yaitu tempat masak, batu pengasah, sapu, lesung dan alunya, tempayan tempat air dengan pemakaian mana ia diikat oleh belenggu dosa.

Tasam kramena sarwasam niskrtyastham maharsibhih,

panca klpta mahayajnah pratyaham grhamedhinam.

Artinya:

Untuk menembus dosa yang ditimbulkan oleh pemakaian kelima alat itu para Maha Rsi telah menggariskan untuk para kepala keluarga agar setiap harinya melakukan pancayadnya.
Adhyapanam brahma yajnah pitr yajnastu tarpanam, homo daiwo balibaurto nryajno 'tithi pujanam.

Artinya:

mengajarkan dan belajar adanya yadnya bagi Brahmana, upacara menghaturkan tarpana dan air adalah kurban untuk para dewa, upacara bali, adalah kurban untuk bhuta dan penerimaan tamu dengan ramah adalah kurban untuk manusia.

Pancaitanyo mahayajnam na hapayati saktitah,

sa grhe'pi wasannityam sunadosairna lipyyate.

Artinya:

ia yang tidak mengabaikan kurban besar yang lima ini selama ia mampu untuk melakukannya, ia tidak dinodai oleh dosa yang dilakukannya pada kelima tempat penyembelihan tadi walaupun ia selalu hidup dan bekerja sebagaimana seorang kepala rumah tangga (Pudja dan Tjok Rai Sudharta, 1976 atau 1977:150-151).

Menyimak makna kutipan sloka-slokadi atas, maka ada beberapa hal penting yang perlu dicatat, seperti berikut ini.

1) Ada lima tempat penting sebagai tempat penyembelihan dalam rumah tangga yang perlu diperhatikan agar kehidupan menjadi tidak ternoda, yaitu : tempat masak, tempat batu pengasah, tempat sapu, tempat lesung dan alunya, dan tempat air atau tempayan.

2) Untuk menebus dosa sebagai akibat dari kelima tempat dan alat tadi, maka umat Hindu agar melakukan panca yadnya setiap harinya;

3) Mengajar dan belajar, menghaturkan tarpana, upacara dengan minyak susu, upacara bali dan menerima tamu dengan ramah adalah lima jenis persembahan bagi umat Hindu. 
4) Siapapun tanpa kecualinya yang dapat melakukan kelima jenis persembahan tersebut, maka yang bersangkutan tidak dinodai oleh dosa, sebagai akibat dari pemaakaian kelima tempat penyembelihan itu.

Demikian sebagai inti dari ajaran agama Hindu menurut menurut sumbernya, guna terbentuknya kader Hindu yang berkualitas yang yang diformulasikan ke dalam tri kerangka agama Hindu, yang sangat adaptif dalam penerapannya materi tattwa, susila, dan upacara agama Hindu merupakan wujud inti atau sari-sari ajaran Veda, yang dalam prakteknya disesuaikan dengan desa kala patra.

\subsection{Upaya Membangun Pribadi Pemuda Hindu Beretika dan Cerdas}

Sesungguhnya ada banyak upaya yang bisa ditempuh dalam membangun pribadi pemuda Hindu yang beretika dan cerdas. Setidaknya dapat dilakukan baik secara perseorangan, secara kelompok, baik dalam keluarga, dalam masyarakat, secara kelembagaan nonformal, secara institusi formal, maupun lainnya lagi yang memiliki kepedulian terhadap upaya untuk meningkatkan kualitas sumber daya manusia Hindu. Tidak ada istilah terbatas atau langkanya upaya yang bisa ditempuh untuk menuju peningkatan kualitas sumber daya manusia Hindu. Kapanpun itu bisa dilakukan siapapun bisa menggerakkan selaku organisatornya. Yang tergolong adalah adanya langkah nyata dan positif ke arah membangun pribadi pemuda Hindu.

Pada sisi lain sering yang menjadi kendala adanya langkahnya sumber materi sajian yang dijadikan pedoman dalam mengupayakannya. Belum lagi masih sedikitnya para figur Hindu, sehingga hal yang dapat dijadikan sebagai faktor penghambat dalam berupaya secara nyata. Kemudian masih jugaada hambatan masalah pendanaan untuk melakukan pengkaderan
Hindu yang berkualitas, maka hal ini secara otoomatis akan menjadi kendala besar dalam mewujudkan cita-cita tersebut. Bila semua itu yang menjadi pemikiran semata, maka upaya apapun yang akan dilakukan pasti saja menimbulkan hambatan dan kebuntuan dalam penyelenggaraan.

Guna mengantisipasi terhadap semua fenomena itu, maka insan-insan Hindu hendaknya memiliki jiwa pantang menyerah serta sedapat mungkin untuk dapat memmberdayakan potensi lokal yang tersedia untuk dimanfaatkan semaksimal mungkin. Tiada upaya yangg tidak akan mencapai suatu hasil. Disini diperlukan juga ada keberanian, tekad yang bulat, semangat yang tinggi, adanya kerjasama dan koordinasi yang baik dengan berbagai lini, sehingga suatu masalah bisa dipecahkan secara bersama-sama dan bebannya dirasakan lebih ringan. Hal inilah yang patut dan terus digalang oleh para pemuda Hindu dimanapun mereka berada.

Beberapa upaya yang bisa ditempuh dalam membangun pribadi pemuda Hindu yang beretika dan cerdas, seperti berikut ini.

\section{a. Melakukan Kegiatan Tirtha Yatra}

Tirta Yatra adalah perjalanan suci ke tempat-tempat yang suci ataupura di sekitar lingkungan atau masyarakat Hindu berada. Kegiatan ini bermakna untuk mendekatkan diri dengan Hyang pencipta atau Hyang Widhi Wasa. Kegiatan ini juga bertujuan untuk menjalin suasana kebersamaan, kekeluargaan, persatuan, serta keharmonisan di antara sesama generasi muda Hindu. Inti dari kegiatan ini adalah melakukan pemujaan dan persembahyangan bersama untuk menghormati Tuhan Yang Maha Esa beserta dengan seluruh prabhawa Tuhan. Dalam kegiatan ini selain melakukan persembahyangan, juga dapat dilakukan kegiatan kerja bhakti atau kebersihan sekitar lingkungan pura. Juga dapat dilakukan wejangan mengenai ajaran agama Hindu dari salah pemuda atau pemudi yang telah memiliki 
wawasan tentang ajaran agama Hindu ataupun materi lainnya yang baik untuk dibicarakan, seperti tentang materi lingkungan, materi susila, materi pengetahuan sosial, materi teknologi dan ilmu pengetahuan, materi seni dan budaya, dan sebagaimana.

Dalam pelaksanaan Tirta Yatraini dapat dipilih beberapa tempat suci yang terdekat atau sesuati kesempatan para pemuda, sehingga adanya kepastian lokasi mengenai pura yang dijadikan tempat Tirta Yatra. Dari kegiatan ini dapat dipetik maknanya yakni untuk meningkatkan wawasan para pemuda tantang keberadaan suatu pura, dapat mengenal lingkungan sekitar, dapat menumbuhkan rasa cinta kasih terhadap potensi alam yang memiliki nilai religius, juga dapat membina disi dan kelompok pemuda yang berlaku sopan, santuna, ramah, suka memelihara, dan sebagainya. Jadi Tirta Yatrasebagai salah satu aktivitas yang positif bagi pemuda Hindu dengan biaya yang relatif murah, namun maknanya sangat kaya dan mulia.

\section{b. Melakukan Kegiatan DharmaTula}

Dharma Tula adalah kegiatan untuk berdialog, berdiskusi, tanggung jawab mengenai materi ajaran agama Hindu. Materi dapat dipilih tentang filsafat atau tattwa, etika atau susila, dan upacara atau ritual selain itu dapat didiskusikan mengenai materi itihasa (mahabharata dan ramayana), materi purana, materi upanisad, materi budaya Hindu dalam susastra Hindu atau sanskriti ca kala natya, materi kepemimpinan Hindu atau niti sastra, materi ekonomi Hindu dan artha sastra, materi politik Hindu atau rajaniti sastra, materi pertanian atau warta, materi agama Hindu dan materi antar agama jika dipandang perlu, dan materi lainnya yang relevan dan sangat akurat untuk dibicarakan oleh pemuda Hindu. Pemilihan topik-topik dharma tula perlu disesuaikan dengan kebutuhan yang bersifat urgent oleh karena sangat bermanfaat bagi pemuda dan juga berguna bagi masyarakat luas.

Mengenai pelaksanaan dharma tula dapat dipilih tempat yang praktis dan sederhana tanpa harus menyewa, misalnya di wantilan suatu pura, di pasraman, di sekolah atau kampus, di tempat terbuka di sekitar lingkungan yang segar dan nyaman, serta di tempat lainya yang mendukung kegiatan tersebut. Kemudian mengenai nara sumber tidak mesti mendatangkan pakar atau tokoh dari jauh, oleh karena akan menghabiskan biaya yang besar. Bisa saja dipilih figur setempat yang memadai wawasan tentang agama Hindu. Tidak itu saja, maka salah seorang pemuda bisa juga tampil sebagai pembicara secara bergiliran sambil melatih diri dan mencari pengalaman sebagai nara sumber. Jika semakin sering dilatih maka hal itu menjadi terbiasa dan berpeluang untuk membuka pintu kecerdasan dalam berpikir, berwacana dan menguasai audien.

\section{c. Melakukan Utsawa Dharma Wacana \\ Utsawa Dharma Wacana yaitu lomba} pidato agama Hindu. Atau lomba wejangan materi-materi agama Hindu sesuai dengan kebutuhan dan keadaan masing-masing daerah. Kegiatan ini dapat dikelola secara sederhana dan murah. Pemuda Hindu dapat mengundang komponen umat Hindu, khususnya bagi generasi muda Hindu, kalangan remaja Hindu, kalangan pelajar (siswa dan mahasiswa), ataupun lapisan masyarakat lainnya yang mendukung kegiatan utsawa dharma wacana yang tujuannya untuk meningkatkan pengetahuan, wawasan, pemahaman, serta bertambahnya teori-teori agama Hindu dalam bentuk wacana atau lisan, sehingga upaya untuk mencerdaskan umat Hindu secara umum dapat menjadi kenyataan.

Topik-topik dalam utsawa dharma wacana dapat ditentukan oleh panitia kecil lomba dengan memohon para pemuka atau tokoh yang memiliki wawasan tentang pidato untuk membantu sebagai jurinya. Sedangkan 
kriteria lomba dapat ditentukan secara spontan yang terkait dengan teknis lomba, seperti : penguasaan materi, relevansi teks, penampilan, penguasaan bahasa (bahasa Indonesia atau bhasa daerah), serta ketepatan waktu lomba. Kriteria ini bisa disesuaikandengan kondisi masing-masing dan kesempatan yang ditentukan oleh panitia lomba, guna diketahui oleh setiap peserta lomba. Jadi media ini adalah sangat efektif bagi pemuda Hindu untuk menggali dan mengekspresikan materi agama Hindu di hadapan publik. Dari penampilan ini sebagai upaya meninggkatkan kecerdasan pemuda Hindu.

\section{d. Melakukan Utsawa Dharma Witarka}

Dharma Witarka adalah kegiatan dialog atau pembicaraan materi agama Hindu yang memiliki kemiripan dengan dharma tula. Dalam kegiatan dharma witarka ini yang ditonjolkan adalah adanya adu kecerdasan dan ketrampilan mengemukakan pendapat secara ratio, cermat, cekatan, tepat, cepat, serta berdasarkan sumber yang akurat mengenai materi yang dibicarakan. Dalam kegiatan ini juga diperlukan adanya dewan juri untuk menilai dari segi ketepatan materi, penguasaan materi, penampilan peserta, penguasaan bahasa atau mengungkapkan secara baik dan benar, ketepatan materi, dan komponen lainnya yang relevan. Sama dengan utsawa dharma gita dan utsawa dharma wacana, maka kegiatan dharma witarka juga dapat dilombakan untuk menggairahkan, membangkitkan, meningkatkan, serta memupuk semangat berkompetisi untuk menguasai memahami materi agama Hindu. Cara ini adalah sangat efektif ...diupayakan secara rutin dan teratur oleh para pemuda Hindu, guna mempertebal semangat keberagamaan Hindu serta semangat keberagamaan Hindu serta semangat untuk mencintai agama Hindu.

Dalam pelaksnaannya bisa saja dilakukan di lingkungan sekolah, kampus, pasraman, lembaga pendidikan dari lmbaga budaya masyarakatt, di sekitar pura, di lingkungan keluarga dalam kapasitas yang sederhana dan memadai. Bila upayaini diwujudkan secara rutin dan teratur, maka diyakini tingkat kecerdasan dan etika hindu dari segenap pemuda Hindu semakin baik dari masa ke masa. Tidak saja itu, juga masa depan pemuda Hindu semakin mantap dalam keberadaannya untuk mengisi pembangunan di bidang agama serta pembinaan generasi muda Hindu menuju Hindu yang berkualitas.

\section{e. Melakukan KegiatanPasraman Yowana}

Kegiatan pasraman yowana merupakan untuk memberikan pendidikan agama Hindu kepada para generasi muda Hindu dalam bentuk yang sederhana sesuai tradisi, adatistiadat, -dresta, kondisi setempat, maupun para pemuka masyarakat lainnya yang peduli dengan aktivitas pasraman agama Hindu. Sifatnya bisa saja secara regular (teratur) maupun insidental (berkala), yang terpenting adalah adanya upaya positif untuk memberikan pembekalan ilmu pengetahuan, teknologi, dan seni kepada pemuda Hindu.

Pelaksanaan pasraman yowana ini dapat dipilih secara sederhana dengan kapasitas waktu yang tidak terlalu lama, adanya figur yang menuntun, tersedianya materi yang sesuai dengan rencana, adanya bentuk kerja sama yang baik dengan berbagai lini guna terlaksananya kegiatan pasraman yowana. Mengenai peserta kegiatan ini dapat dipilih para remaja Hindu yang memiliki minat dan bakat belajar yang tinggi untuk mendalami materi ajaran agama Hindu. Selain itu juga memberikan kesempatan kepada setiap pemuda Hindu untuk memancing berpikir kritis, kreatif, aktif, dinamis, adaptif, luwes, cerdas, dan bertanggung jawab terhadap perkembangan kepemudaan serta dinamika kehidupan beragama Hindu. 


\section{f. Melakukan Diklat Manajemen dan Organisasi}

Kegiatan Diklat Manajemen danOrganisasi merupakan kegiatan yang sangat penting bagi Hindu itu harus siap menghadapi tantangan dan kemajuan jaman, yang sewaktu-waktu selalu berubah dan berkembang. Hal ini dapat diantisipasi melalui pelaksanaan pendidikan dan pelatihan singkat di bidang manajemen dan organisasi. Dalam praktek kehidupan beragama Hindu bahwa aktivitas hidup dalam berorganisasi dirasakan masih tergolong terbatas dalam sekala yang tergolong mapan. Guna meningkatkan kemapanan di bidang manajemen dan organisasi, maka diklat ini (DMO) adalah sebagai salah satu upaya alternatif untuk mengunggah semangat para pemuda Hindu.

Dalam kegiatan DMO ini lebih banyak ditekankan pada bagaimana para pemuda Hindu dalam mengelola organisasi kepemudaan misalnya, atau organisasi lainnya yang telah eksis dalam masyarakat Hindu dengan tetap menggembangkan segalakelebihan dan peluang dari organisasi tersebut. Selanjutnya segala bentuk kelemahan dan hambatan bisa dicarikan solusinya secara tepat guna. Dengan kegiatan ini para pemuda bisa membuat rencana, bisa melaksanakan secara bersama, bisa mengelola secara lebih profesional, dan mengendalikab kegiatan scara sempurna dengan menekan sekecil mungkin segala yang bersifat negatif serta bentuk lainnya yang positif.

\section{g. Kegiatan Pelatihan Kepemimpinan, Manajemen dan Organisasi}

Kegiatan ini juga ada kemiripan dengan kegiatan DMO, hanya saja ada tambahan dalam diklat ini yakni berupa materi kepemimpinan. Dalam kegiatan ini bahwa materi kepemimpinan sangat penting, oleh karena keberadaan pemimpin sebagai pengawas, penilai, pengendali, dan penggerak suatu organisasi diperlukan model pemimpin yang ideal. Bagaimana yang dikatakan pemimpin yang ideal itu, maka peluang diklat ini sebagai medianya untuk memprkenalkan dan menambah wawasan para pemuda Hindu untuk berkiprah dalam kancah yang lebih luas dalam era globalisasi.

Materi kepemimpnan, manajemen, dan organisasi adalah materi di bidang pelayanan publik yang bersifat urgent sangat perlu dimiliki oleh parapemuda Hindu. Hal ini biasanya dipandang sebelah mata saja, oleh karena perhatian tentang materi ini tergolong masih kurang peminatnya. Jika kegiatan PKMO ini dijadikan sebagai media yang baik untuk menjembatani para pemuda Hindu, maka diyakini bahwa kualitas pemuda Hindu ke depan menjadi lebih unggul dan berkualitas.

\section{h. Melakukan Utsawa Dharma Gita}

Kegiatan utsawa dharma gitaadalah pelaksanaan lomba nyanyan lagu-lagu keagamaan Hindu. Kegiatan ini sebenarnya sudah lazim dan sering dilakukan oleh umat Hindu Indonesia. Pelaksanaan utsawa dharma gita telah berkali-kalidilangsungkan, baik di tingkat desa, tingkat kecamatan, tingkat kabupaten, tingkat provinsi, maupun tingkat nasional. Selain itu, bahwa kgiatan utsawa dharma gita ini merupakan media untuk umat Hindu melakukan kompetisi antara yang satu dengan yang lainnya secara positif untuk memperoleh prestasi yang terbaik dalam olah vokal perspektif agama Hindu.

Materi utsawa dharma gita pada umumnya adalah lagu-lagu keagamaan Hindu yang meliputi kidung, sloka, phalawakya, macepat, dan kakawin. Materi kidung materi berupa kidung yang lazim dilagukan dalam upacara dewa yajna dan pada umumnya berbahasa Bali, Jawa, Dayak, Sasak, ataupun dari kidung lainnya dari wilayah Indonsia. Materi slokaadalah materi lagu yang diambilkan dari sumber-sumber suci agama Hindu, seperti dari pustaka suci Veda berupa rgVeda, yajurVeda, samaVeda, atharvaVeda, bhagavadgita, sarasamuscaya, manawa- 
dharmasastra, purana, upanisad, itihasa, dan sumber suci lainnya dalam pustaka suci agama Hindu. Materi slokaadalah ajaranajaran agama Hindu yang berbahasa Sansekerta.

Kemudian phalawakya adalah lagu keagamaan Hindu yang secara umum berbahasa Jawa Kuna yang diambil dari beberapa pustaka suci Hindu seperti dalam Sarasamuscaya, Mahabharata, Ramayana, Niti Sastra, slokantara, Silakrama, maupun sumber lainnya dalam ajaran agama Hindu. Materi macepat adalah materi dari beberapa pupuh yang biasanya berbahasa Jawa Kuna atau Bali diantaranya sinom, pucung, ginada, ginanti, pangkur, maskumambang, dan yang lainnya. Sedangkan materi kakawin adalah nyanyian suci laghu yaitu ketentuan berat dan ringan, panjang dan pendek, keras dan lembut, serta ketentuan alainnya. Sumber materi kakawin adalah sumber suci agama Hindu berupa kakawin mahabharata, kakawin ramayana, kakawin bharata yuda, kakawin sutasoma, kakawin arjuna wiwaha, kakawin bhomantaka, kakawin, siwaratri kalpa, kakawin niti sastra dan sebagainya.

Jadi pelaksanaan utsawa dharma gita ini sesungguhnya untuk meningkatkan kecintaan para pemuda terhadap nilai-nilai pendidikan agama Hindu yang terkandung dalam dharma gita tersebut. Prakteknya adalah dilakukan pada tempat tertentu oleh panitia atau oleh umat Hindu pada umumnya dengan melibatkan warga Hindu dari unsur pemuda, pemudi, pelajar, para wanita, kelompok pecinta dharma gita, dan umat Hindu pada umumnya. Dalam penampilan lomba ini dapat dilakukan penjurian untuk menentukan siapa sebagai pemenangnya. Biasanya kriterianya adalah ekpresi suara, penampilan, nada atau irama, kekompakan, serta kriteria lainnya yang dipandang perlu.

\section{i. Melakukan Pasraman Brahmacarya}

Pasraman Brahmacarya adalah upaya menggalang kelompok belajar dalam masyarakat Hindu untuk dituntun peningkatan kualitas belajar agama Hindu serta materi lainnya yang terkait dengan ilmu pngetahuan, seni dan teknologi. Kegiatan ini adalah sebagai bentuk dari umat Hindu untuk selalu belajar dan berguru untuk menambah wawasan dan ilmu pengetahuan.

Dalam penerapan sistem belajar pada pasraman brahmacarya ini maka wajib ada penuntun suci berupa dang acarya atau guru kerohanian, yang memiliki tugas spiritual atau tugas kesucian, guna menuntun, mendampingi, mengawasi, memberikan keteladanan, serta panutan lainnya secara teori maupun praktis. Sistem ini memerlukan tempat khusus sebagai tempat tetap untuk melakukan kegiatan belajar dan praktek keagamaan Hindu. Jadi tempat khusus itu berupa ashram atau pasraman, sejenis padepokan atau pesantren. Dalam masyarakat Hindu di Bali lebih populer dengan istilah sekaa pesantian. Jadi ashram ini adalah secara khusus sebagaitempat belajar bagi umat Hindu tanpa memandang usia dan ashram belakangan ini, jadi kalau di Jawa hal ini sudah dikenal baik oleh masyarakat Hindu.

\section{j. Melakukan Dana Punya ke Panti Asuhan}

Kegiatan dana punya adalah upaya positif untuk memmberikan bantuan atau sumbangan berupa material atau sejenisnya kepada para umat Hindu yang membutuhkannya. Salah satunya adalah dilakukan di pantai asuhan, oleh karena di tempat itu ada bbanyak umat yang diasuh, dibina, dituntut oleh para pengelolanya untuk bisa melanjutkan hidupnya termasuk juga kegiatan belajar agama Hindu. Panti asuhan adalah salah satu bentuk atau wadah untuk membina umat Hindu menuju peningkatan kualitas diri. Hal ini juga menjadi bagian bentuk kepedulian para pemuda Hindu.

Model lainnya selain dari pada asuhan, bisa saja berupa yayasan yang diupayakan oleh umat Hindu untuk menampung para generasi muda yang yatim, yang yatim piatu, anak yang cacat, 
anak yang terlantar, anak yang miskin, orang tua jompo, orang yang lemah fisiknya dan sebagainya. Bila para pemuda Hindu memiliki kepedulian terhadap wadah ini itu berarti adanya nilai kemanusiaan, nilai prihatin, sertakesusilaan bagi pemuda itu sendiri. Jadi perannya disini adalah turut membantu dari pendidikan, bantuan ceramah agama Hindu, bantuan dana, serta bantuannya yang bernilai positif.

\section{k. Melakukan Kegiatan Kerja Baktidi Pura}

Kerja bhakti di pura merupakan kegiatan cinta dan peduli terhadap suasana, kondisi, serta keberadaan suatu pura. Wujud kegiatan pemuda Hindu terhadap tempat sucinya dapat dilakukan dengan melakukanpenanaman bunga dan perindang lainnya yang menghijaukan lingkungan pura. Dalam hal ini bahwa pemuda selalu dapat saja melakukan reboisasi atau penghijauan terhadap lingkungan pura yang nampak gersang, gundul, polusi, dan kondisinya masih tercemar oleh faktor lainnya.

Selainkegiatan kebersihan di pura, maka sekaligus dapat dilakukan upaya pengenalan jenis tanaman upakara, pengenalan bunga yang bisa digunakan untuk keperluan yajna, jenis material yang ada di sekitar pura yang bernilai religius, bernilai usadha, bernilai kebutuhan bhoga, dan sebagainya. Jadi kegiatan kerja bhakti ke suatu pura tidak semata hanya tujuan merawat pura supaya tetap apik dan asri, tetapi juga untuk membangkitkan nilai spirit para pemuda Hindu sehingga pada akhirnya dapat terwujud pemuda yang berkualitas, pemuda yang handal yakni pemuda yang suputradan suputri.

\section{l. Melakukan Kegiatan Sosial ke Masyarakat}

Melakukan kegiatan sosial dalam masyarakat dimaksudkan untuk mengenal kondisi secara langsung di tengah-tengah masyarakat luas. Pemuda Hindu perlu banyak belajar di tengah masyarakat, oleh karena tempat yang paling efektif untuk membina berbagai pengalaman serta menimbailmu pengetahuan sosial dan ilmu pengetahuan lainnya. Adapun kegiatan sosial yang bisa dilakukan adalah membantu masyarakat yang tertimpa bencana alam gempa bumi, bencana banjir, bencana gunung meletus, bencana tanah longsor, bencana angin ribut, bencana tabrakan kereta api atau mobil dan yang sejenis lainnya. Upaya memberikan pertolongan kepada khalayak umum adalah perilaku susila dan terpuji bagi semua insan di dunia ini.

Wujud bantuan sosial kepada masyarakat yang tertimpa bencana dapat dilakukan memaberikan bantuan berupa bantuan pakaian, makanan, uang, bantuan tenaga, bantuan ide atau pemikiran positif untuk memberikan solusi terbaik terhadap masalah yang dihadapinya. Semua jenis kegiatan itu selain bernilai relawan, bernilai persembahan atau yajna, bahwa hal itu adalah perilaku susila atau subhakarma. Kebaikan itu akan mendatangkan kebaikan juga bagi pelakunya. Tidak ada salahnya para pemuda Hindu berlaku baik kepada insan manusia di dunia ini, yang pada akhirnya juga dapat berpahala kebaikan bagi para pemuda Hindu yang berkarma kebaikan. Hal ini telah diajarkan dalam ajaran yajna, karmaphala, ajaran susila, ajaran sraddha, ajaran bhakti, serta ajaran suci lainnya dalam agama Hindu.

\section{m. Melakukan Kegiatan Sosial ke Masyarakat}

Kegiatan ini adalah secara khusussebagai media menggalang, memupuk, mengembangkan, serta membangkitkan semangat kompetisi para pemuda-pemudi Hindu untuk aktivitas yang brrsifat kompleks yang terkait dengan aktivitas keagamaan Hindu. Awalnya kegiatan ini secara rutin dilakukan di negeri Hindu di Bharatiya. Belakangan ini juga dilakukan di Indonesia, termasuk di Jawa dan di Bali. Kalau di Bali ada pacentokan sekaa teruna, yang secara khusus sebagai wadah untuk memupuk semangat para generasi muda 
Hindu di tingkat banjar pakraman maupun di tingkat desa pakraman.

Jenis kegiatan yang bisa dilakukan adalah berupa kegiatan pentas seni, pentas budaya, pentas seni keagamaan Hindu, apresiasi susastra Hindu, serta kegiatan lainnya yang terkait dengan tumbuh suburnya seni budaya yang dijiwai oleh nafas ajaran agama Hindu. Termasuk juga seni lukis, seni karawitan, seni tari, seni suara, seni sakrral agama Hindu, dan seni lokal yang masih murni keberadaannya yang masih dilestarikan oleh umat Hindu setempat sesuai desa kala patra. Kegiatan yuva mahotsava ini bertujuan untuk mengembangkan dan melestarikan berbagai jenis seni (kala) dan budaya Hindu (Hindu darma sanskriti). Jadi masih banyak lagi kegiatan atau upaya yang bisa dijadikan pembangkit semangat keberagaman Hindu menuju kecerdasan dan pengalaman etika Hindu.

\section{SIMPULAN}

Pentingnya para pemuda-pemudi Hindu untuk memahami makna ajaran agama Hindu mlalui tattwa, juga sangat bermanfaat pula materi etika atau tata susila Hindu untuk dijadikan landasan berpijak, berlaku, dan berkarma, agar gerak lakunya mengarah kepada perbuatan yang baik (susila atau subhakarma). Hal ini tidak merupakan citacita pemuda Hindu, oleh karena cita-cita pemuda Hindu adalah untuk terrwujudnya kader muda Hindu yang bijaksana (gunamantha), arif (prajna), cerdas wisesa), berlaku baik (sadhu), berbuat benar (sukarma atau subhakarma), rajin bekerja (karmani) bukan malas bekerja (akarmani), berlaku penuh nilai (mulya karma), serta menjadi pemuda-pemudi yang baik dan benar (suputrasuputri).

Dalam rangka untuk mewujudkan tujuan tersebut di atas, maka ada beberapa upaya positif yang dapat dilakukan bagi peningkatan kualitas pemuda-pemudi Hindu, antara lain : melakukan kegiatan Tirta Yatra, melakukan kegiatan dharma tula, melakukan utsawa dharma wacana, melakukan kegiatan dharma witarka, melakukan kegiatan pasraman yowana, melakukan diklat manajemen dan organisasi, kegiatan pelatihan kepemimpinan, manajemen dan organisasi, melakukan utsawa dharma gita, melakukan pasraman brahmacarya, melakukan dana punya ke panti asuhan, melakukan kegiatan kerja bakti di pura, melakukan kegiatan sosial ke masyarakat, dan melakukan kegiatan yuva mahotsava. Bilamana semua upaya di atas bisa diwujudnyatakan dalam realitas hidup dan kehidupan para pemuda Hindu, diyakini bahwa cita-cita untuk membangun pemuda Hindu beretika dan cerdas bisa menjadi kenyataan. Tidak hanya itudiyakini dapat terwujudnya kader Hindu yang berkualitas bagi dirinya, keluarga, masyarakat, bangsa dan negara Indonesia tercinta. Hal ini diperlukan upaya secara rutin dan upaya dari berbagai pihak, baik oleh yang bersangkutan, para orang tua, para pemuka atau tokoh, para pengajar, para pembina di tingkat nonformal maupun formal, serta pihak-pihak lainnya lagi yang memiliki kompetensi di bidangnya masing-masing. Sebagai kata kuncinya adalah upaya membangun pemuda Hindu yang beretika dan cerdas berdasarkan ajaran agama Hindu, sebagai targetnya adalah terwujudnya pemuda Hindu yang suputra dan suputri.

\section{DAFTAR PUSTAKA}

Abu, Rivai (Ed.). 2002. "Sistem Kesatuan Hidup Setempat Daerah Bali". Balai Pengkajian dan Pemanfaatan Sejarah dan Tradisi Bali.

Ali, Mukti, dkk., 1998. Agama Dalam Pergumulan Masyarakat Kontemporer. Yogya : pT. Tiara Wacana. 
Anonim. 2000. " HImpunan Keputusan Seminar Kesatuan Tafsir Terhadap AspekAspek Agama Hindu I-XV". Milik Pemda Bali.

Apte, V.M. 1997. "Ritual-Ritual Veda". Artikel dimuat dalam WHD No. 364-365, Agustus 1997.

Azizy, A. Qodri A. 2003. Pendidikan (Agama) Untuk Membangun Etika Sosial (Mendidik Anak Sukses Masa Depan : Pandai dan Bermanfaat). Semarang : CV. Aneka Ilmu.

Geriya, I Wayan, 2000. Transformasi Kebudayaan Bali Memasuki Abad XXI. Denpasar. Percetakan Bali.

Hariono, 2006. "Memahami Manusia : Aspek Jasmani Untuk Rohani”. Artikel dimuat dalam WHD No. 479, Desember 2006.

Kadjeng, I Nyoman, dkk. 1999. Sarasamuscaya. Surabaya: Paramita.

Kadjeng, dkk. 2000. Sarasamuscaya. Pemda Bali.

Kadjeng I Nyoman dkk. 2006. "Sarasamuscaya". Milik Pemkab Bangli.

Karmini, Ni Wayan, dkk. 2002. Agama Hindu untuk SMU Kelas I-III. Jakarta Selatan : Ganeca Exact Kebayoran Baru.

Mantra, IB.2006. "Bhagawadgita”. Milik Pemda Bangli.

Mardana, I Nyoman dkk, 2002. Mari Belajar Agama Hindu untuk SD Kelas I-VI. Jjakarta Selatan : Penerbit Ganeca Exact Kebayoran Baru.

Maswinara, I Wayan. 1997. Bhagawadgita. Surabaya : Paramita.

Maswinara, I Wayan. 1998. Ilmu Pengetahuan dan Spiritual Berdasarkan Veda. Surabaya : Paramita.
Maswinara, I Wayan. 1999. Sistem Filsafat Hindu. Surabaya: Paramita.

Maswinara, I Wayan. 2003. Sistem Filsafat Hindu. Surabaya : Paramita.

Moelyono. Djokosantoso, 2004. Beyond Leadership 12 Konsep Kepemimpinan. Jakarta : Gramedia.

Netra, AA Gde Oka, 1998. "Brosur Pembinaan Remaja Hindu" Ditjen Bimas Hindu dan Budha Departemen Agama RI.

Oka, I Gusti Agung, 1993. Slokantara. Jakarta : Hanuman Sakti.

Pendit, Ny S. 2002. Bhagawadgita. Jakarta. PT. Gramedia Pustaka Utama.

Pudja, Tjok Rai Sudharta. 2002. Manawadharmasastra. Jakarta : CV. Nursatama Lestari.

Pudja, 2002. Manawadharmasastra. Jakarta :CV. Felita Nursatama Lestari.

Pudja, 2005. Bhagawadgita. Surabaya : Paramita.

Punyatmadja, IB Oka, 1992. Silakrama. Denpasar : Upada Sastra.

Putra, I Nyoman Darma. 2004. Bali Menuju Jagadhita : Anek Perspektif. Denpasar : PT. Offset BP.

Sivananda, Sri Svami. 2003. Intisari Ajaran Hindu. Surabaya : Paramita.

Subagiasta, I Ketut. 2005. “Ajeg Agama Hindu Modal Utama Menuju Ajeg Bali”, dalam buku Dialog Ajeg Bali Perspektif Pengamalan Agama Hindu. Surabaya : Paramita.

Subagiasta, I Ketut. 2006. "Etika Pendidikan Agama Hindu Dalam NAskah Silakrama". Artikel dimuat dlama WHD No. 477 Oktober 2006 dan 479 Desember 2006. 
Sudarsana, I. K. (2014). Kebertahanan Tradisi Magibung Sebagai Kearifan Lokal dalam Menjaga Persaudaraan Masyarakat Hindu. In Seminar Nasional (No. ISBN: 978-602-71598-0-8, pp. 137-143). Fakultas Brahma Widya IHDN Denpasar.

Sudarsana, I. K. (2016). Meningkatkan Perilaku Kewirausahaan Wanita Hindu melalui Pemberian Pelatihan Upakara. In
Seminar Nasional (No. ISBN: 978-60272630-5-5, pp. 79-85). Pusat Studi Gender dan Anak LP2M IHDN Denpasar.

Sudharta, Tjok Rai, 2003. Slokantara Untaian Ajaran Etika. Surabaya : Paramita.

Sudiyo. 2002. Pergerakan Nasional Mencapai dan Mempertahankan Kemerdekaan. Jakarta : Rineka Cipta. 